Research Article

\title{
High-Isolation UWB MIMO Antenna with Multiple X-Shaped Stubs Loaded between Ground Planes
}

\author{
Minghuan Wang $(\mathbb{D}$, Jingchang Nan, and Jing Liu \\ School of Electronics and Information Engineering, Liaoning Technical University, Huludao 125105, China \\ Correspondence should be addressed to Minghuan Wang; 944959060@qq.com
}

Received 2 September 2021; Revised 29 October 2021; Accepted 13 November 2021; Published 2 December 2021

Academic Editor: Miguel Ferrando Bataller

Copyright (C) 2021 Minghuan Wang et al. This is an open access article distributed under the Creative Commons Attribution License, which permits unrestricted use, distribution, and reproduction in any medium, provided the original work is properly cited.

\begin{abstract}
A miniaturized ultra-wideband multiple-input multiple-output (UWB MIMO) two-port antenna with high isolation based on FR4 is designed in this article. The size of the antenna is only $18 \times 28 \times 1.6 \mathrm{~mm}^{3}$. The MIMO antenna consists of two identical antenna elements symmetrically placed on the same dielectric substrate in opposite directions. By loading three crossed X-shaped stubs between two unconnected ground planes, high isolation and good impedance matching are achieved. The working frequency band measured by this UWB MIMO antenna is $1.9-14 \mathrm{GHz}$, and the isolation is kept above $20.2 \mathrm{~dB}$ in the whole analysis frequency band. Good radiation characteristics as well as envelope correlation coefficient (ECC, <0.09), mean effective gain (MEG), and channel capacity loss (CCL) in the passband meet the requirements of the application, which can be applied to the UWB wireless communication system. To verify the applicability of the proposed method for enhancing the isolation between antenna elements, the two-port antenna structure was extended to a four-port antenna structure. In the case of loading the $\mathrm{X}$-shaped stubs to connect to the ground plane, the isolation of the antenna is maintained above $15.5 \mathrm{~dB}$ within $1.7-14 \mathrm{GHz}$.
\end{abstract}

\section{Introduction}

With the rapid development of the wireless communication field, people's requirements for communication quality and high speed increase accordingly. To improve the system capacity (by applying multiplexing technology) and reliability (by applying diversity technology), the multiple-input multiple-output (MIMO) technology is proposed. By using the advantages of these two aspects, the transmission signal is appropriately encoded and decoded. MIMO is a technology that uses multiple antenna elements at both ends of the transmitter and receiver. To make the MIMO system work normally, it is necessary to reduce the correlation of the antenna elements in the system [1]. For this reason, several methods for reducing the correlation between elements in an antenna array in a MIMO system have been proposed, for example, defect ground structure decoupling [2, 3], parasitic stub decoupling [4-6], neutralization line decoupling [7-9], diversity technology decoupling [10-12], and electromagnetic band-gap (EBG) structure decoupling [13, 14].
Especially in ultra-wideband (UWB) systems, it is difficult to achieve long-distance transmission due to the disadvantages of low radiation power and multipath fading. Therefore, the combination of UWB technology and MIMO technology can transmit multiple paths at the same time. Without increasing the antenna's radiation power, the transmission distance of the UWB system is significantly improved [15]. The ultra-wideband multiple-input multiple-output (UWB MIMO) technology has been deeply studied by many scholars because of its high transmission rate, good communication quality, and large channel capacity.

In the design of UWB MIMO antennas, the ground plane structure has a separate ground plane $[16,17]$ and a common ground plane. In the design process of the same MIMO antenna structure, a separate ground plane is usually better than a shared ground plane in terms of isolation between antenna elements. Considering that the MIMO antenna connected to the ground plane will be better applied to the commercial field [18], the decoupling structure of the MIMO antenna that shares the ground plane is further analyzed. 
Reference [19] loads an inverted T-slot at the top of the center of the common ground plane of two rectangular antenna elements so that the isolation of the antenna is maintained above $24.5 \mathrm{~dB}$ within $3-5 \mathrm{GHz}$. Loading a vertical rectangular slot near the bottom of the ground plane reduces the isolation of the antenna in the range of $5-10.6 \mathrm{GHz}$ and keeps the isolation of the antenna above $20 \mathrm{~dB}$ within $3.1-10.6 \mathrm{GHz}$. Reference [20] reduces the coupling between antenna elements by loading slotted rectangular parasitic stubs on the ground plane and keeps the isolation of the antenna above $20 \mathrm{~dB}$ within 2-13.7 GHz. Reference [21] connects two circular radiating patches by loading a wideband neutralization line between two antenna elements. The current coupling of the ground plane is reduced so that the isolation of the antenna is maintained above $22 \mathrm{~dB}$ within $3.1-5 \mathrm{GHz}$. Reference [22] designed a four-port MIMO antenna. Through the use of polarization diversity technology, the isolation of the antenna is maintained above $17 \mathrm{~dB}$ within $3-13.2 \mathrm{GHz}$. In addition, loading a set of slots on the ground plane further reduces the envelope correlation coefficient of the MIMO antenna. Reference [23] designed a four-port double-sided UWB MIMO antenna. By loading the EBG structure on the front and back of the antenna, the isolation of the antenna was kept above $20 \mathrm{~dB}$ within $3-11 \mathrm{GHz}$.

This article proposes a two-port UWB MIMO antenna that uses multiple cross $\mathrm{X}$-shaped stubs to achieve high isolation and a large working frequency band between the ground planes of the antenna elements. While connecting the two ground planes, most of the current is concentrated on the loaded branches, reducing the mutual coupling between the antenna elements. Through measurement, it can be known that the isolation in the working frequency band $1.9-14 \mathrm{GHz}$ is all greater than $20.2 \mathrm{~dB}$, and the envelope correlation coefficient $(\mathrm{ECC}<0.09)$, mean effective gain (MEG), and channel capacity loss (CCL) meet the requirements of practical applications [24]. The designed twoport MIMO antenna is extended to a four-port MIMO antenna with adjacent antenna elements placed orthogonally. Similarly, X-shaped stubs are loaded between the ground planes of the antenna elements placed in the opposite direction, and the two intersecting stubs make the antenna structure share the same ground plane. The simulation shows that the isolation of the antenna is maintained above $15.5 \mathrm{~dB}$ within $1.7-14 \mathrm{GHz}$. It is confirmed that the method of improving isolation adopted by the two-port antenna is also applicable to the design of the four-port MIMO antenna. The smaller antenna size $\left(34 \times 34 \times 1.6 \mathrm{~mm}^{3}\right)$ makes it easier to integrate with modern wireless communication equipment.

\section{UWB MIMO Antenna Design}

2.1. Design of UWB Antenna. In order not to increase the overall size of the antenna design, the antenna structure is kept compact. UWB characteristics are achieved by using a method of digging grooves on the original microstrip patch antenna structure to change the surface current distribution. We design an improved UWB antenna based on a rectangular radiating patch and microstrip feeder with FR4 material on the dielectric substrate [25]. The structure diagram of the UWB antenna finally designed is shown in Figure 1. Some design parameters of the UWB antenna can be calculated using the wavelength $(\lambda)$ corresponding to the low frequency $(3.7 \mathrm{GHz})$ of the UWB antenna [26].

The long of the rectangular radiation patch $\left(L_{P}\right)$ satisfies the following equation:

$$
\frac{\lambda}{10} \leq L_{P} \leq \frac{\lambda}{5}
$$

The effective length of the antenna is the sum of the long of the rectangular radiating patch $\left(L_{P}\right)$ and the length of the microstrip feeder $\left(L_{f}\right)$, as shown in the following equation:

$$
\left(L_{P}+L_{f}\right) \approx \frac{\lambda}{5}
$$

The length of the feed gap is the difference between the length of the microstrip feed line $\left(L_{f}\right)$ and the length of part of the ground plane $\left(L_{g}\right)$, and it satisfies the following equation:

$$
0.02 \lambda \leq\left(L_{f}-L_{g}\right) \leq 0.04 \lambda \text {. }
$$

The thickness of the dielectric substrate $(H)$ can be calculated by the following equation:

$$
H \approx 0.02 \lambda \text {. }
$$

Through the use of electromagnetic simulation software to further optimize the antenna structure and calculated parameters, the specific dimensions of the antenna area are marked in Figure 1. The three antenna structures and the simulated $S_{11}$ results are shown in Figure 2. It can be seen from Figure 2 that by cutting off the triangular grooves at the edges of the rectangular radiating patch and the microstrip feeder of the antenna, the UWB characteristics with a working frequency band of $3.7-14 \mathrm{GHz}$ are realized.

To study the effect of truncating the long side of the triangular slot on the antenna performance, the other parameters remain unchanged. Figures 3(a) and 3(b) show the $S_{11}$ results of the different long sides of the triangular slot truncated by radiation patch $\left(L_{C}\right)$ and the different long sides of the triangular slot truncated by the microstrip feeder $\left(L_{F C}\right)$, respectively. It can be seen from Figure 3(a) that with the increase of $L_{C}$, the low-frequency point of the antenna in the working frequency band decreases, but the amplitude is smaller. When $L_{C}=6 \mathrm{~mm}$, the performance of the antenna at high frequencies is better than that of the other two values, so $L_{C}=6 \mathrm{~mm}$ is selected as the optimal parameter. It can be seen from Figure 3(b) that with the increase of $L_{F C}$, the working frequency band of the antenna is expanded, and the maximum working frequency band is realized when $L_{F C}=7 \mathrm{~mm}$. Therefore, $L_{C}=6 \mathrm{~mm}$ and $L_{F C}=7 \mathrm{~mm}$ are used as the optimal long-side values of the triangular slot truncated by the antenna's radiating patch and the microstrip feeder.

2.2. Design of the Connection Structure of the Ground Planes. Two identical antenna elements of the above design are placed in opposite directions on the same dielectric substrate 


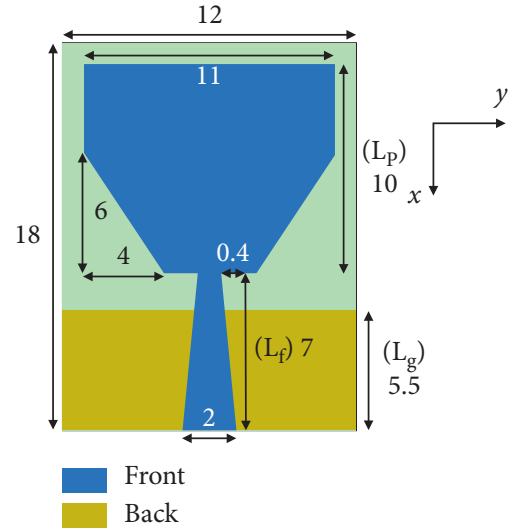

Figure 1: Schematic diagram of UWB antenna structure (mm).

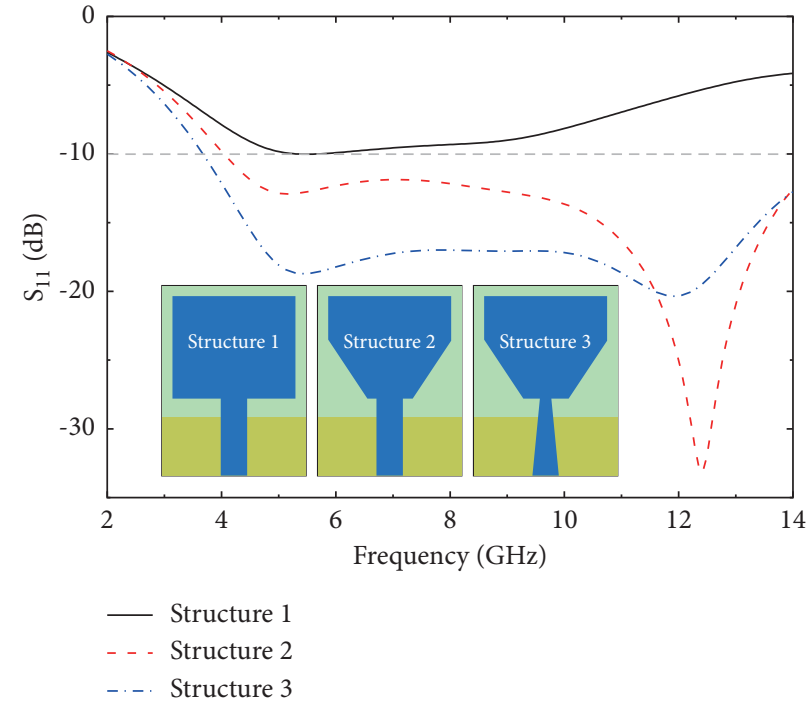

FIgURE 2: Simulated $S_{11}$ results of three UWB antenna structures.

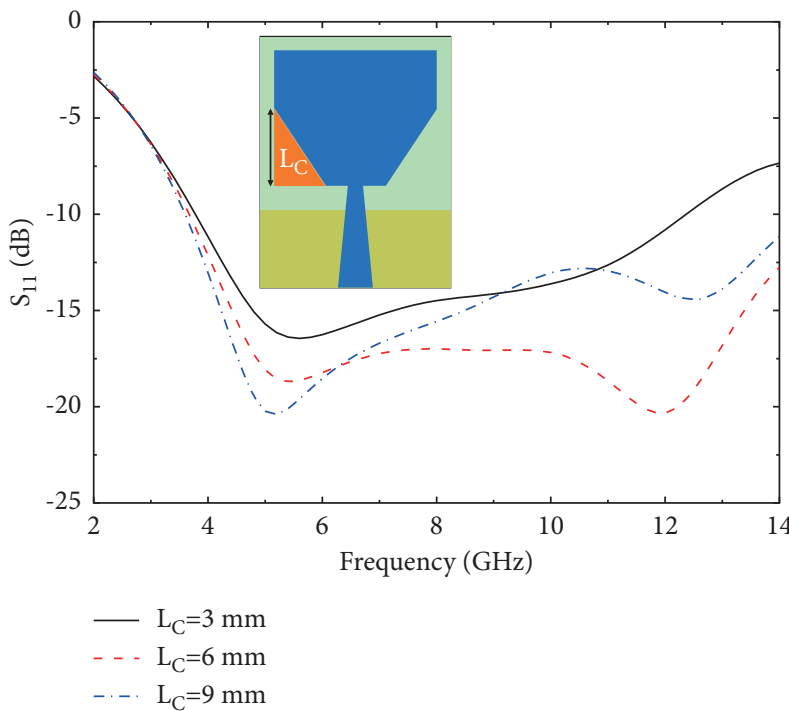

(a)

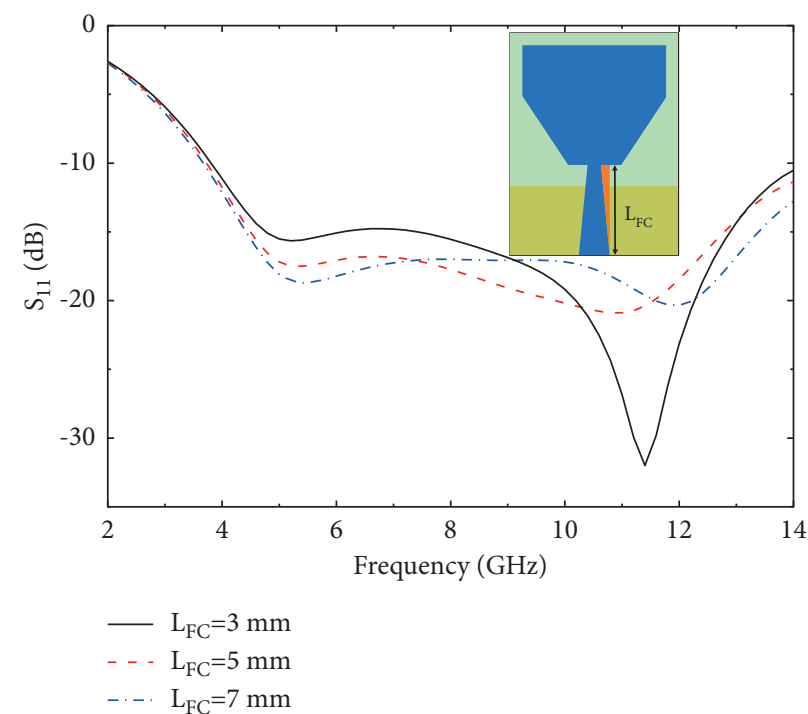

(b)

FIgURE 3: $S_{11}$ simulation results of different long-side values of truncated triangular slots. (a) $L_{C}$. (b) $L_{F C}$. 
to form a two-port MIMO antenna, and the spacing between the elements is $4 \mathrm{~mm}$. The material of the dielectric substrate is FR4, the relative permittivity of the substrate is 4.4 , the loss tangent is 0.02 , and the thickness is $1.6 \mathrm{~mm}$. Figure 4 shows a schematic diagram of the UWB MIMO antenna structure without any decoupling structure.

Figure 5 shows the $S$-parameter results obtained in the electromagnetic simulation software of the antenna structure and the surface current distribution diagram at $5 \mathrm{GHz}$. It can be seen from the simulation result graph that when the left port of the antenna is connected to the excitation source and the right port is connected to a $50 \Omega$ load, a large amount of current is coupled to the right antenna element, which reduces the irrelevance between the antenna elements. Since the two ground planes of the antenna element are not connected, there is no ground current coupling. The reason for the formation of this coupling mainly comes from the spatial coupling. At the same time, the isolation of the antenna remains above $13.6 \mathrm{~dB}$ in the $3.2-14 \mathrm{GHz}$ working frequency band. The low isolation between antenna elements makes it impossible to use in MIMO systems. Although the working frequency band of the antenna meets the design requirements of the UWB antenna, in practical applications, the MIMO antenna needs to share the ground plane with the system, which requires the antenna elements in the MIMO antenna to share the ground plane. MIMO antennas that do not share the ground plane are not suitable for wireless communication systems [27], so the antenna elements need to be ground-connected.

Figure 6 shows a schematic diagram of the connection structure of the three ground planes. To further determine the ground connection structure and obtain better UWB MIMO antenna performance indicators, Figure 7 shows the $S$-parameter simulation results of three connection structures. It can be seen from Figure 7 that the return loss of A1 connection structure and A2 connection structure at $3.7-6.6 \mathrm{GHz}$ and $3.7-6.9 \mathrm{GHz}$ is greater than $-10 \mathrm{~dB}$, and this frequency band cannot work normally, thereby reducing the overall working frequency band of the antenna. Also, the isolation in the passband is greater than $12.9 \mathrm{~dB}$ and $16.2 \mathrm{~dB}$, respectively. A3 connection structure achieves good impedance matching within $1.9-14 \mathrm{GHz}$ while achieving isolation greater than $18.4 \mathrm{~dB}$. In summary, loading an $\mathrm{X}$-shaped stub between ground planes can more effectively improve the isolation between antenna elements and the working frequency band. For A1 and A2 connection structures, as the coverage area of the connection stubs increases, the isolation of the antenna in the passband is improved, while the $S_{11}$ result hardly changes. This article will specifically discuss the impact of the number of loaded $\mathrm{X}$-shaped stubs on antenna isolation in Section 2.3 to achieve higher isolation between antenna elements.

To further study the influence of different connection structures on antenna performance, Figure 8 shows the surface current distribution diagrams of A1, A2, and A3 at $3 \mathrm{GHz}$. In the figure, the currents distributed on the feeders and radiating patches in the right antenna element of $\mathrm{A} 3$ structure are significantly smaller than those of A1 and A2 structures, and most of the current is concentrated on the

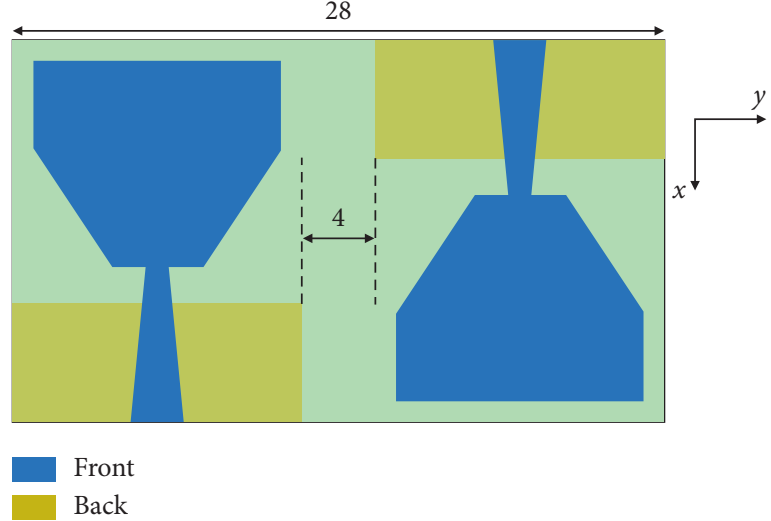

FIgURE 4: Schematic diagram of UWB MIMO antenna structure without decoupling structure $(\mathrm{mm})$.

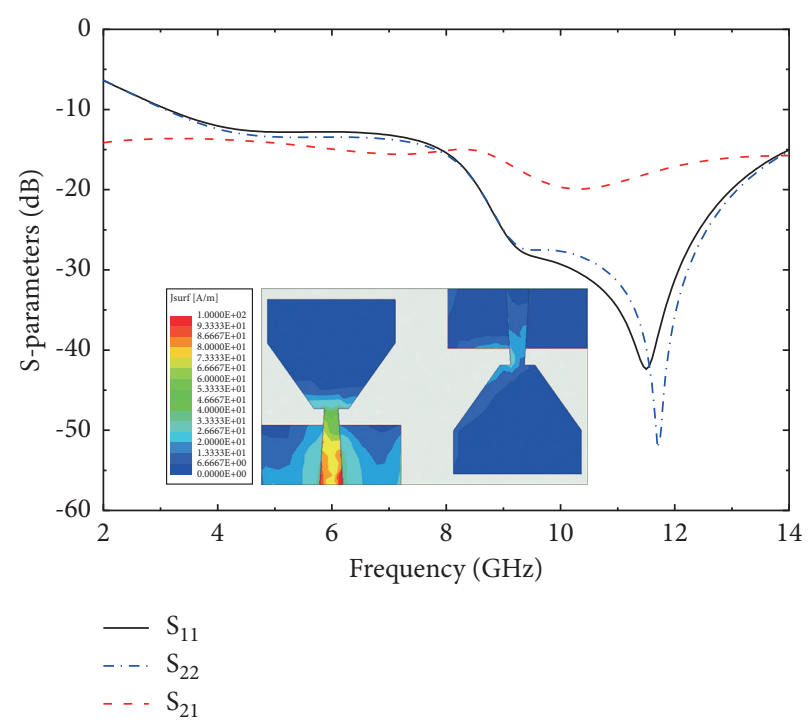

FIGURE 5: Simulated $S$-parameters of UWB MIMO antenna without loaded decoupling structure and the surface current distribution under $5 \mathrm{GHz}$.

loaded X-shaped branch. Thus, it can be verified that A3 structure loaded with an X-shaped stub in Figure 7 can achieve higher isolation between antenna elements and effectively reduce the mutual coupling between the elements. Different connection structures make the surface current distribution paths of the left antenna element connected to the excitation source different so that the frequency bands at which the antenna achieves impedance matching are different.

2.3. Influence of the Number of X-Shaped Stubs. Figure 9 shows the $S$-parameter simulation results for different numbers of X-shaped stubs. The width of each stub connecting with the ground is $0.5 \mathrm{~mm}$, and the interval between each stub is $0.5 \mathrm{~mm}$. It can be seen from the figure that with the increase in the number of X-shaped stubs, the working frequency band of the MIMO antenna has hardly changed (1.9-14 GHz), while the isolation of the antenna at low 


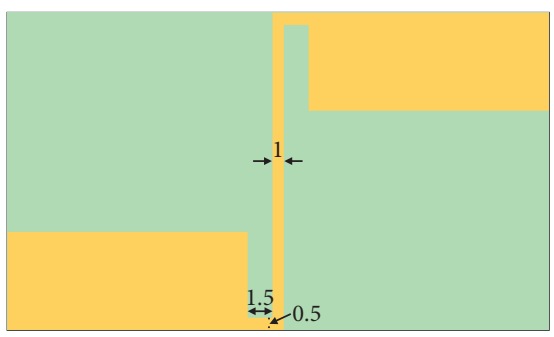

(a)

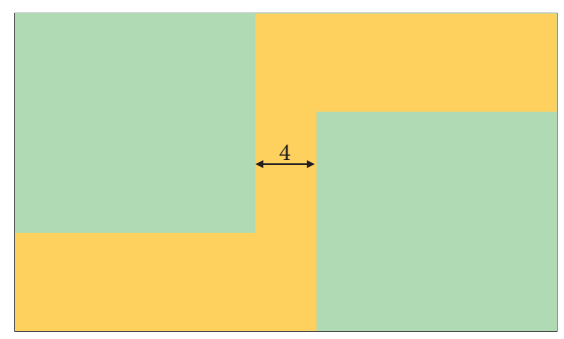

(b)

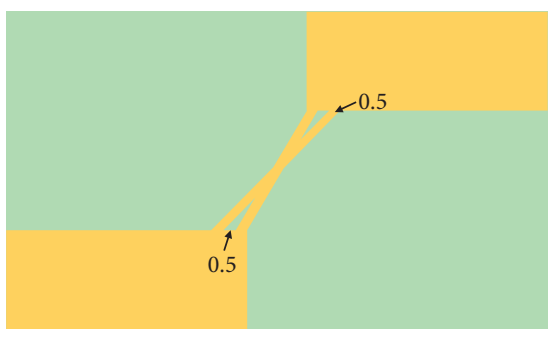

(c)

Figure 6: Schematic diagram of the connection structure of the two ground planes. (a) A1. (b) A2. (c) A3.

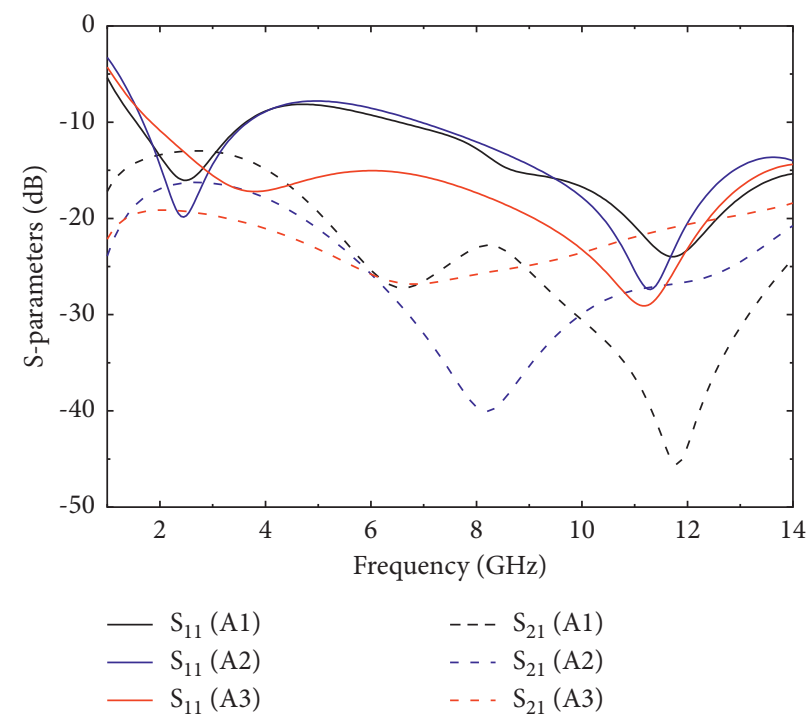

FIGURE 7: S-parameter simulation results of three connection structures.
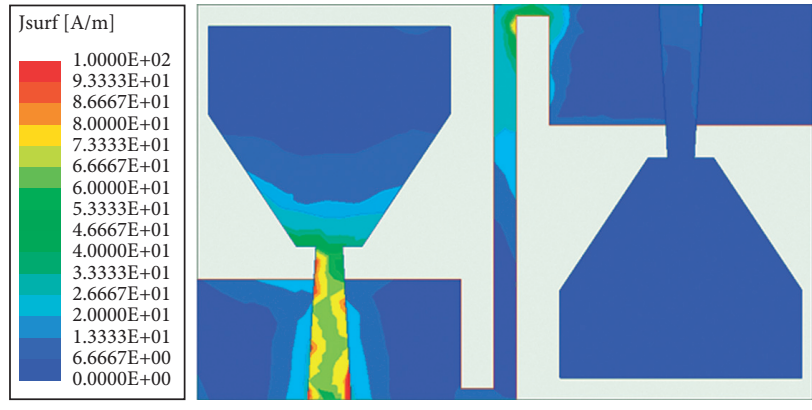

(a)

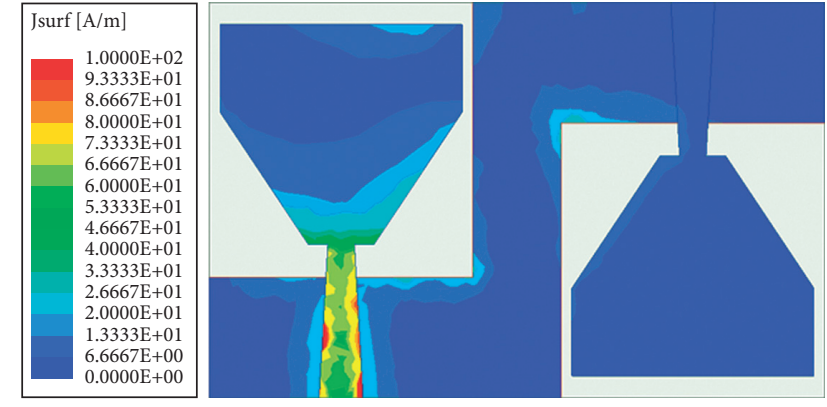

(b)
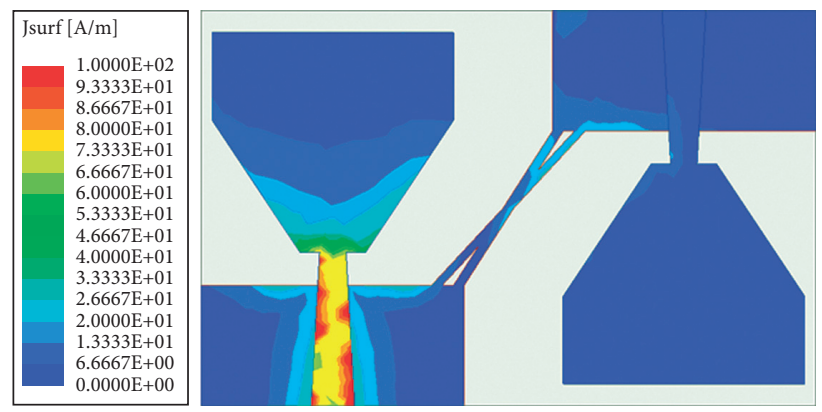

(c)

FIgURE 8: Surface current distribution diagrams of three antenna structures at $3 \mathrm{GHz}$. (a) A1. (b) A2. (c) A3. 


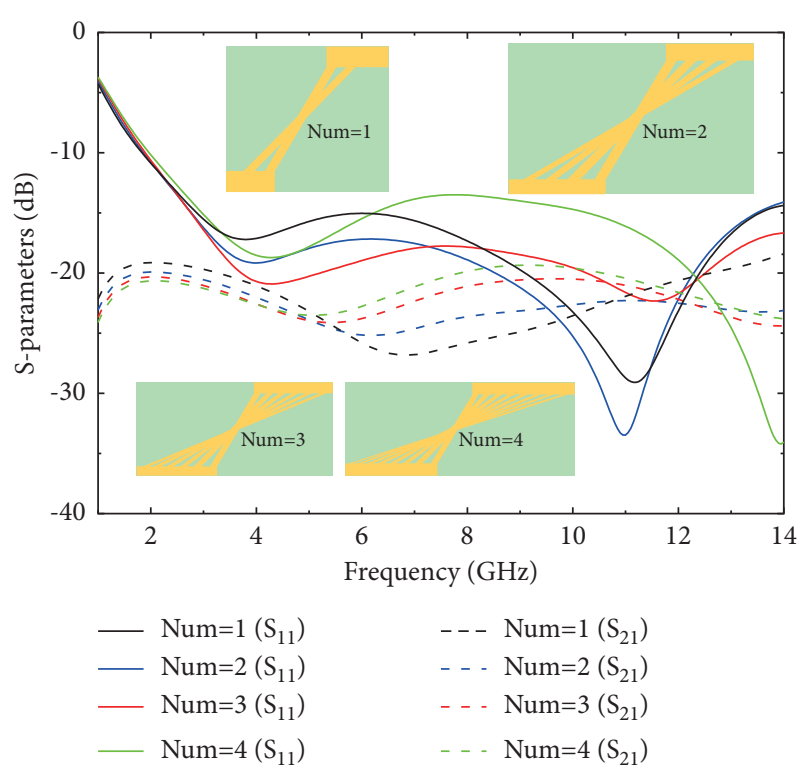

FIGURE 9: $S$-parameter simulation results of different numbers of $\mathrm{X}$-shaped stubs.

frequencies is gradually improved. Although the isolation at low frequencies is further improved when four X-shaped stubs are loaded, the isolation at high frequencies around $8-10 \mathrm{GHz}$ is less than $20 \mathrm{~dB}$, which makes the antenna isolation greater than $19.3 \mathrm{~dB}$ in the working frequency band. Therefore, the antenna structure loaded with three $\mathrm{X}$-shaped stubs is used as the two-port UWB MIMO antenna decoupling structure designed in this article. While achieving the miniaturization of the antenna $\left(18 \times 28 \times 1.6 \mathrm{~mm}^{3}\right)$, the isolation of the antenna is maintained above $20.3 \mathrm{~dB}$ within $1.9-14 \mathrm{GHz}$.

Figure 10 shows the surface current distribution diagram of the antenna structure with different numbers of X-shaped stubs at $9 \mathrm{GHz}$. It can be seen from the figure that as the number of stubs increases, the current coupling between antenna elements increases at this frequency. The current coupling situation corresponds to the value of $S_{21}$ at this frequency in Figure 9, which verifies the consistency of the results.

2.4. Design of Four-Port UWB MIMO Antenna. On the basis of the decoupling principle adopted by the designed twoport UWB MIMO antenna, the adjacent antenna elements are placed orthogonally to expand into a four-port UWB MIMO antenna. Similarly, an X-shaped stub is loaded between the ground planes of two antenna elements placed in opposite directions, and the two intersecting stubs are connected to the ground planes so that the antennas share the same ground plane. The structure of the four-port UWB MIMO antenna is shown in Figure 11. The simulated $S$ parameter results are shown in Figure 12. It can be seen from Figure 12 that the working frequency band of the designed four-port antenna is $1.7-14 \mathrm{GHz}$, the isolation between antenna elements $S_{12}, S_{14}, S_{23}$, and $S_{34}$ is greater than $15.5 \mathrm{~dB}$, and $S_{13}$ and $S_{24}$ are greater than $16.1 \mathrm{~dB}$. Therefore, the isolation of the designed four-port antenna is greater than $15.5 \mathrm{~dB}$ within $1.7-14 \mathrm{GHz}$, achieving good isolation between antenna elements. It is verified that the $\mathrm{X}$-shaped stub connected to the ground plane of the two-port element described in Section 2.2 achieves better isolation and is also applicable to the four-port antenna design.

To study the influence of the number of different $\mathrm{X}$-shaped stubs on the performance of the four-port antenna, Figures 13 and 14 show the $S$-parameter simulation results of two, four, and six X-shaped stubs and the current distribution diagram at $5 \mathrm{GHz}$, respectively. Taking into account the symmetry of the antenna elements, the performance of one element can be derived from the performance of other units, so only the simulation results of $S_{11}$, $S_{12}$, and $S_{13}$ are given. To ensure the compactness of the antenna design, the four antenna elements are distributed in a limited space. It can be seen from the figure that as the number of stubs increases, the distance between the stubs and the upper surface antenna element decreases. As a result, the current coupled to the stub is extended to the adjacent antenna elements, thereby reducing the overall isolation of the antenna and changing the working frequency band of the antenna. To this end, two X-shaped stubs will be added as the decoupling structure of the designed four-port antenna.

\section{Results and Discussion}

3.1. S-Parameters. In the design process of the UWB MIMO antenna, this article uses electromagnetic simulation software to simulate and optimize the antenna structure and combine the measurement results of the vector network analyzer to comprehensively discuss the performance of the antenna. Considering the symmetry of antenna elements, the performance of one element can be derived from the performance of other elements. Therefore, only the $S$-parameters of the left element are given here. Figure 15 shows the fabricated design of the two-port UWB MIMO antenna. Figure 16 shows the measured $S$-parameter results of the UWB MIMO antenna. The working frequency band of the antenna measurement is $1.9-14 \mathrm{GHz}$, and the isolation in the whole working frequency band is greater than $20.2 \mathrm{~dB}$, which has excellent isolation performance. The measurement and simulation results are roughly the same. The main reason for the error is that the measurement environment is not completely shielded, and there are many electromagnetic interferences around. The accuracy of antenna processing, the welding of joints, and the quality of dielectric substrate plates can all cause similar deviations.

3.2. Radiation Characteristics. Figure 17 shows the radiation pattern of the two-port UWB MIMO antenna simulation and measurement. Figures $17(\mathrm{a})-17(\mathrm{~d})$ show the radiation patterns at $4 \mathrm{GHz}, 6 \mathrm{GHz}, 8 \mathrm{GHz}$, and $10 \mathrm{GHz}$ frequency points. Each figure contains the co-polarization and crosspolarization patterns of the xoz-plane (E-plane) and the yozplane (H-plane). The left port of the antenna is connected to the excitation source, and the right port is connected to a $50 \Omega$ load. It can be seen from the figure that the cross- 


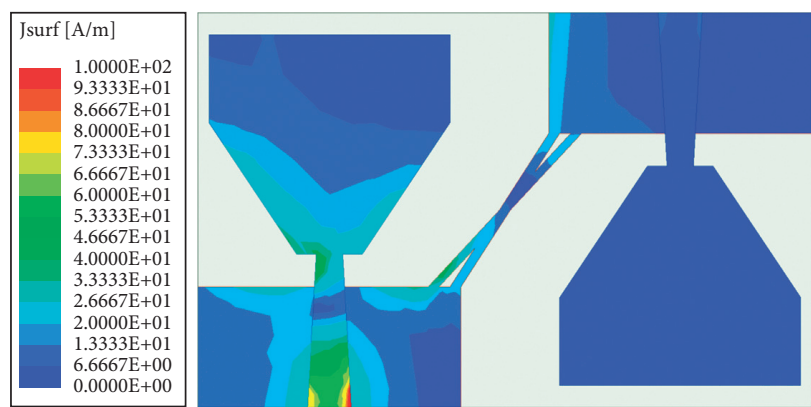

(a)
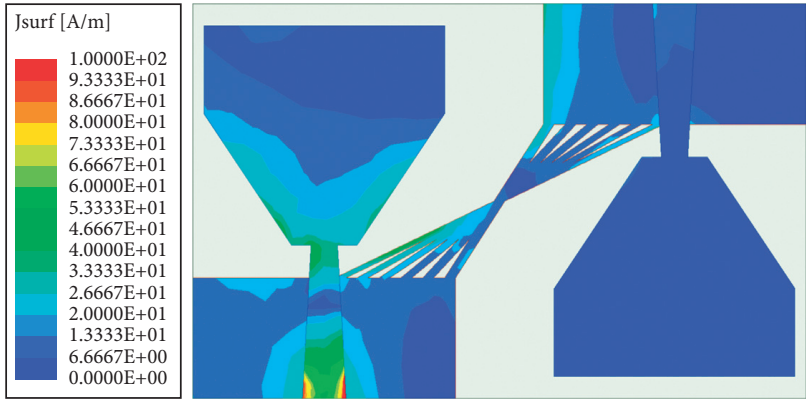

(c)

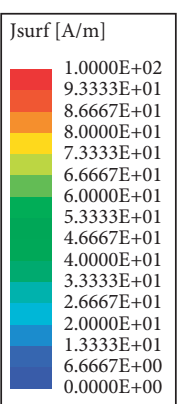

$0.0000 \mathrm{E}+00$

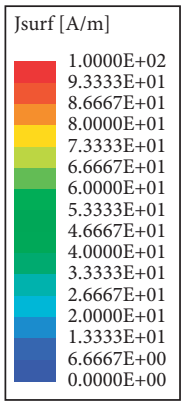

$.0000 \mathrm{E}+00$

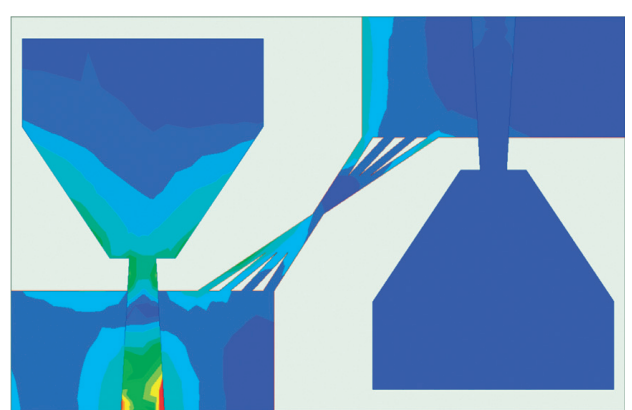

(b)

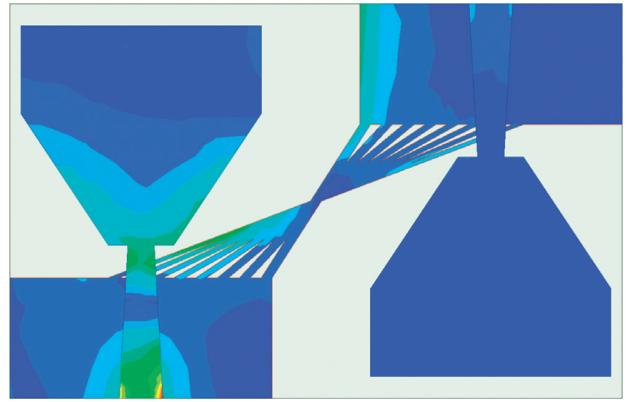

(d)

Figure 10: Surface current distribution of two-port antenna with different numbers of X-shaped stubs at 9 GHz. (a) Num $=1$. (b) Num $=2$. (c) $\mathrm{Num}=3$. (d) Num $=4$.

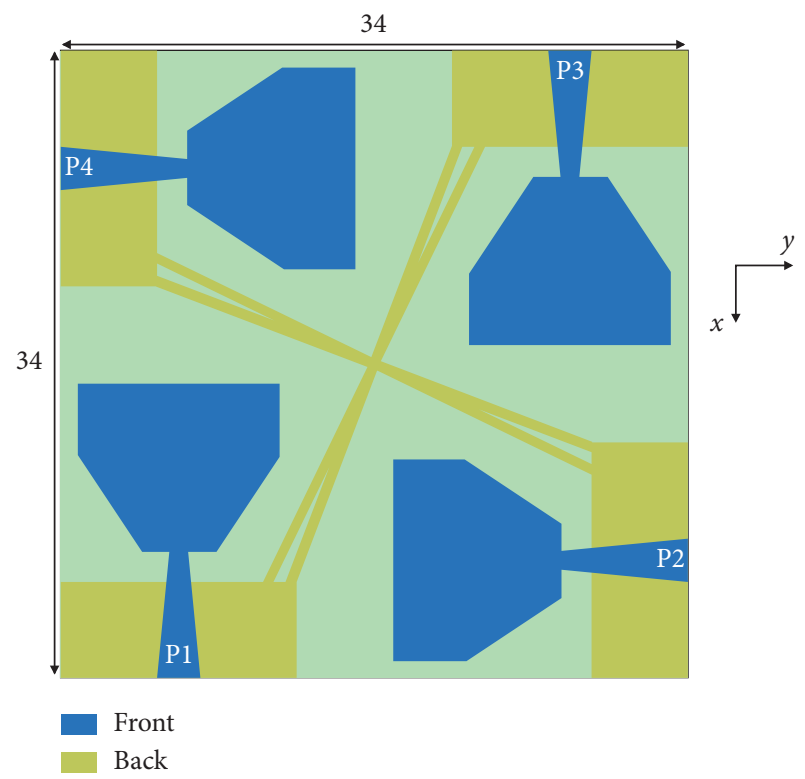

FIgURE 11: Schematic diagram of the structure of the four-port UWB MIMO antenna (mm).

polarization pattern of the xoz-plane maintains bidirectional radiation. The co-polarization pattern of the yoz-plane maintains good omnidirectional radiation characteristics. As the frequency increases, although the shape of the copolarization pattern on the xoz-plane and the cross-polarization pattern on the yoz-plane is distorted, the antenna generally exhibits better omnidirectional radiation characteristics in the passband range.

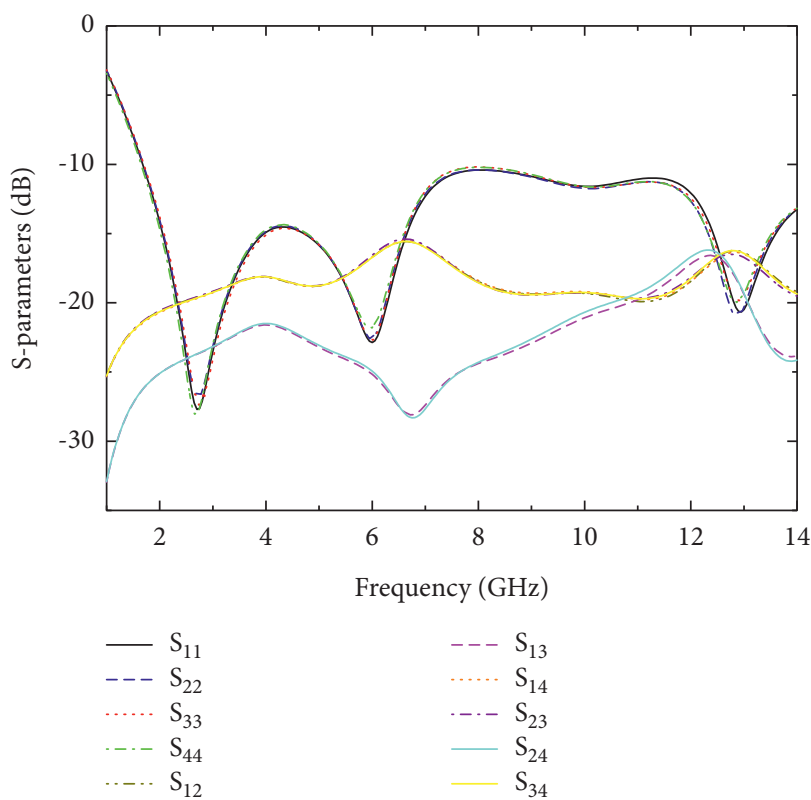

Figure 12: $S$-parameter simulation results of four-port antenna.

Figure 18 shows the simulated and measured gain plots of the two-port antenna. In the working frequency band, the fluctuation range of the simulated gain value is $0.6-6.7 \mathrm{dBi}$, and the fluctuation range of the measured gain value is $0.4-4.8 \mathrm{dBi}$. Due to errors in physical processing and interference from the measurement environment, the maximum gain of the measurement antenna is weaker than the simulation result. 


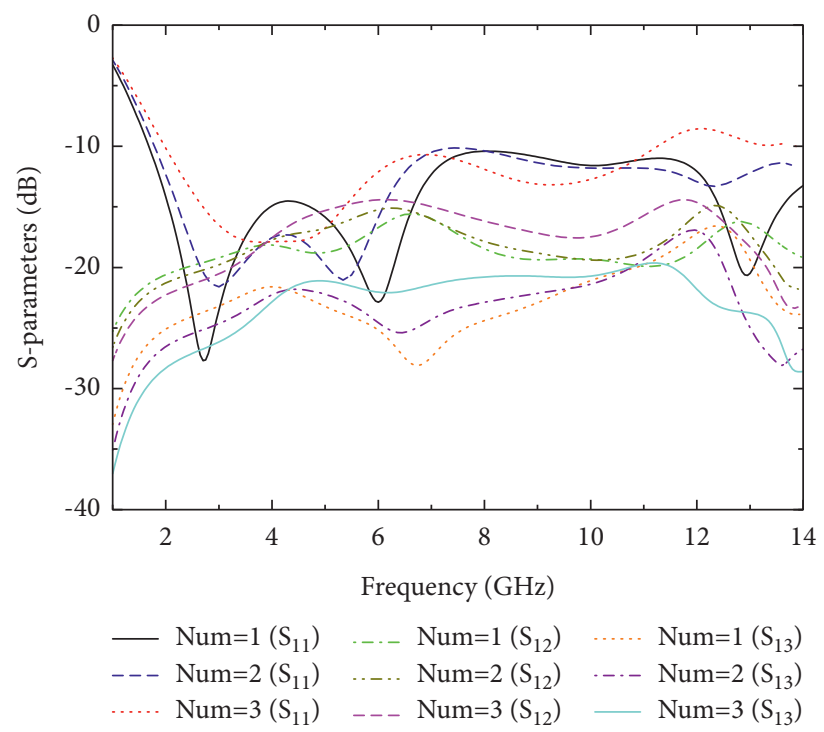

FIGURE 13: S-parameter simulation results of different numbers of X-shaped stubs of four-port antenna.

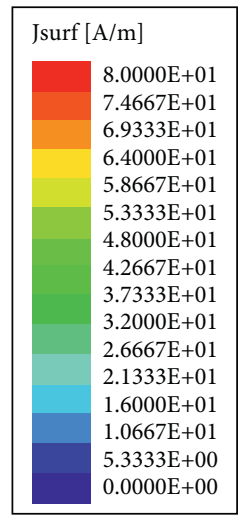

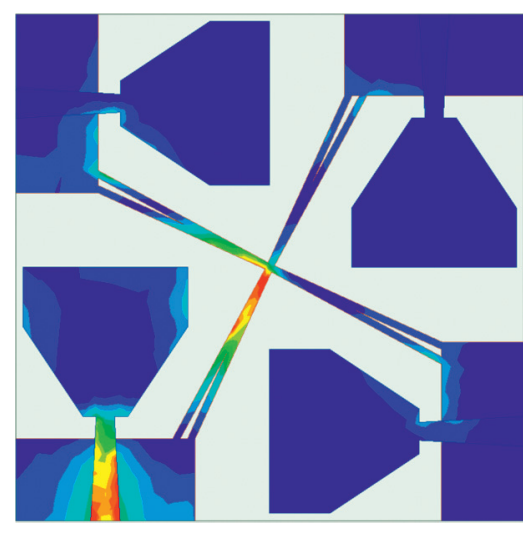

(a)
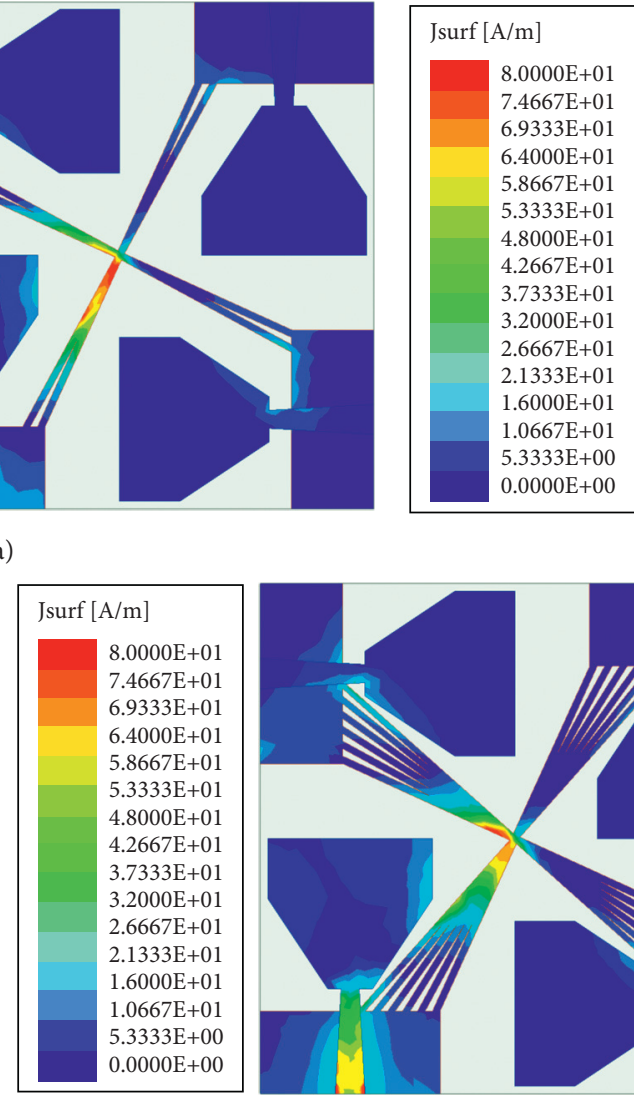

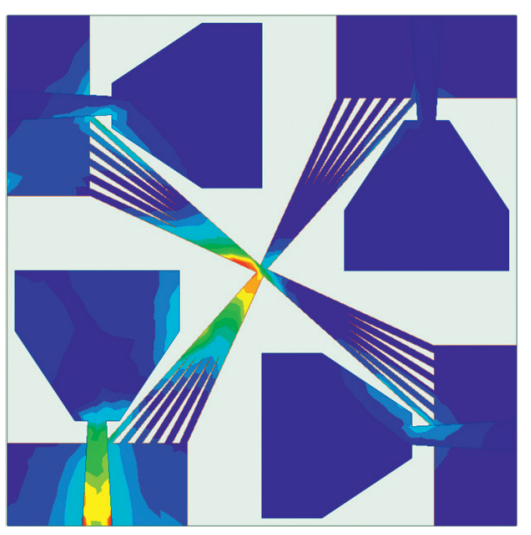

(c)

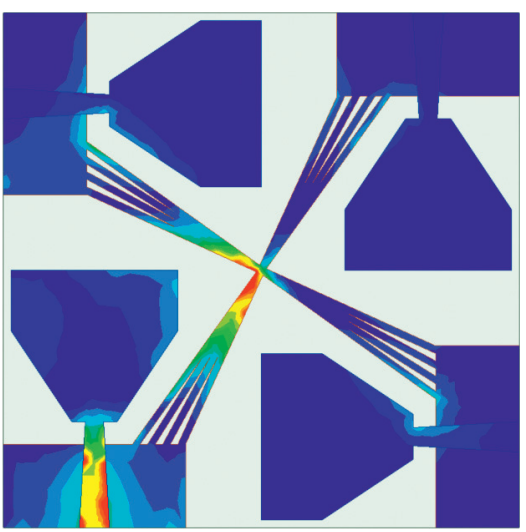

(b) 


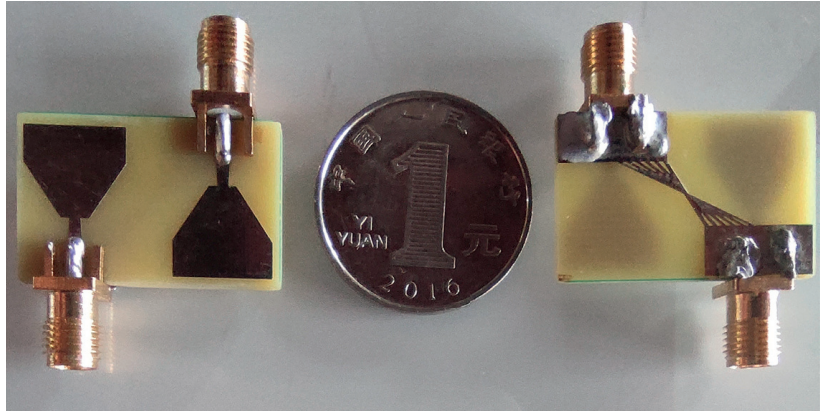

FIGURE 15: Fabricated image of the two-port UWB MIMO antenna.

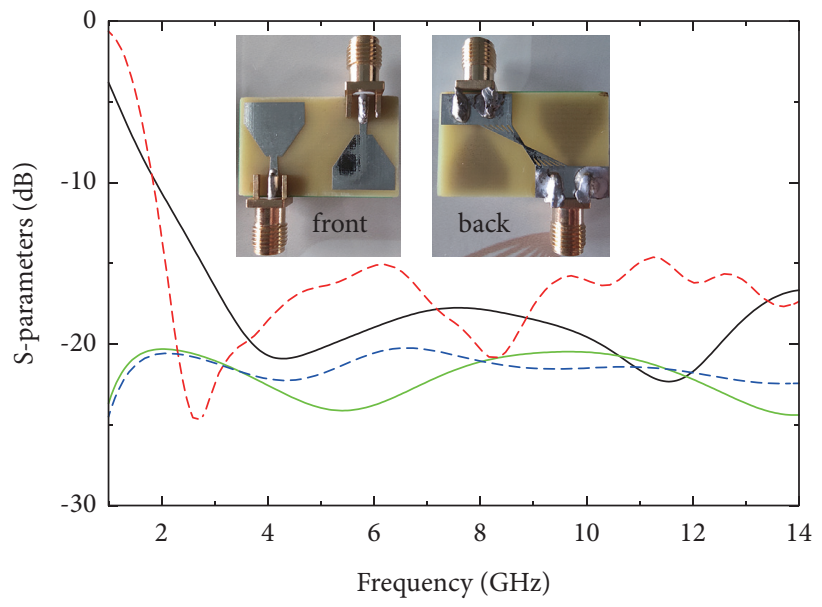

$\begin{array}{ll}-S_{11} \text { simulated } & ---S_{11} \text { measured } \\ -S_{21} \text { simulated } & ---S_{21} \text { measured }\end{array}$

Figure 16: Graph of measured S-parameter results.

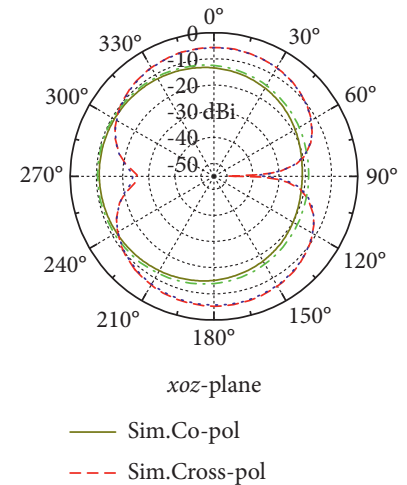

(a)

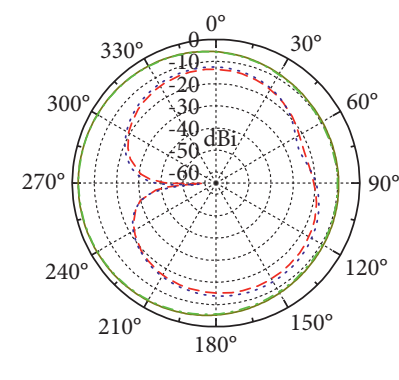

yoz-plane

-.- Meas.Co-pol

.... Meas.Cross-pol

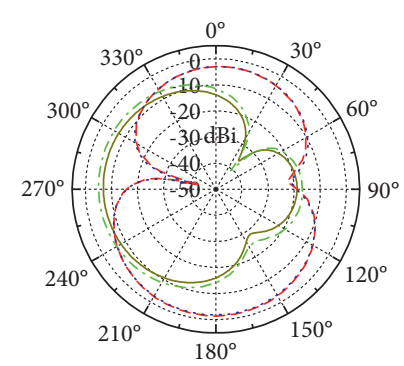

$x o z$-plane

— Sim.Co-pol

--- Sim.Cross-pol

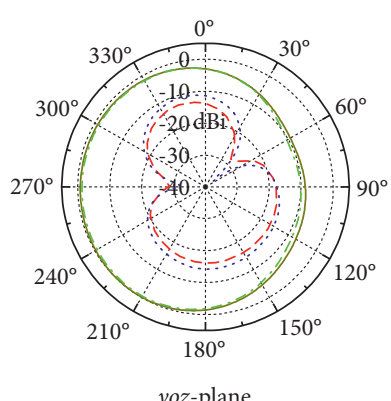

-..- Meas.Co-pol

..... Meas.Cross-pol

(b)

Figure 17: Continued. 


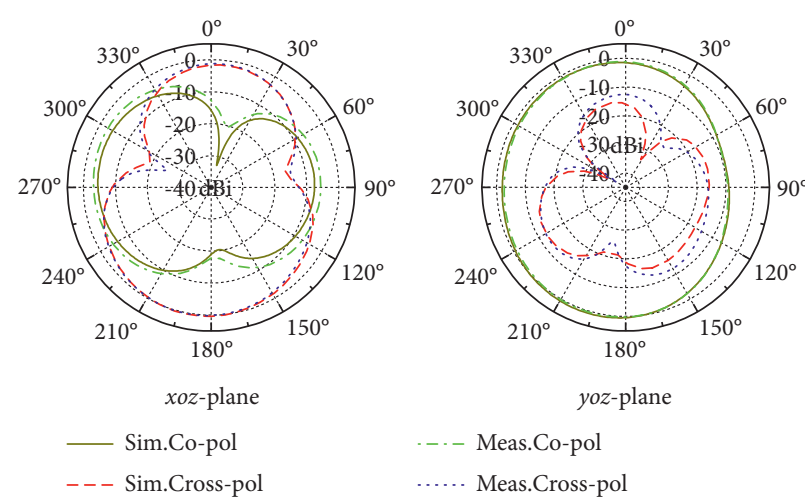

(c)

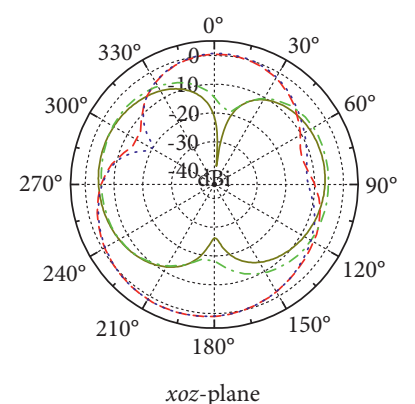

— Sim.Co-pol

- - - Sim.Cross-pol

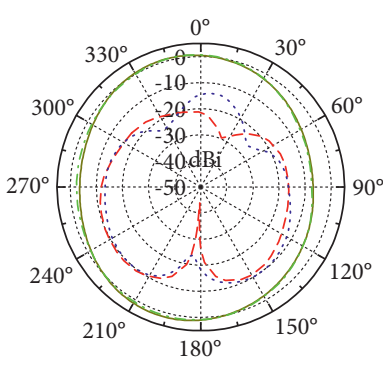

yoz-plane

-...- Meas.Co-pol

...... Meas.Cross-pol

(d)

FIgURE 17: Radiation pattern of two-port antenna simulation and measurement at (a) $4 \mathrm{GHz}$, (b) $6 \mathrm{GHz}$, (c) $8 \mathrm{GHz}$, and (d) $10 \mathrm{GHz}$.

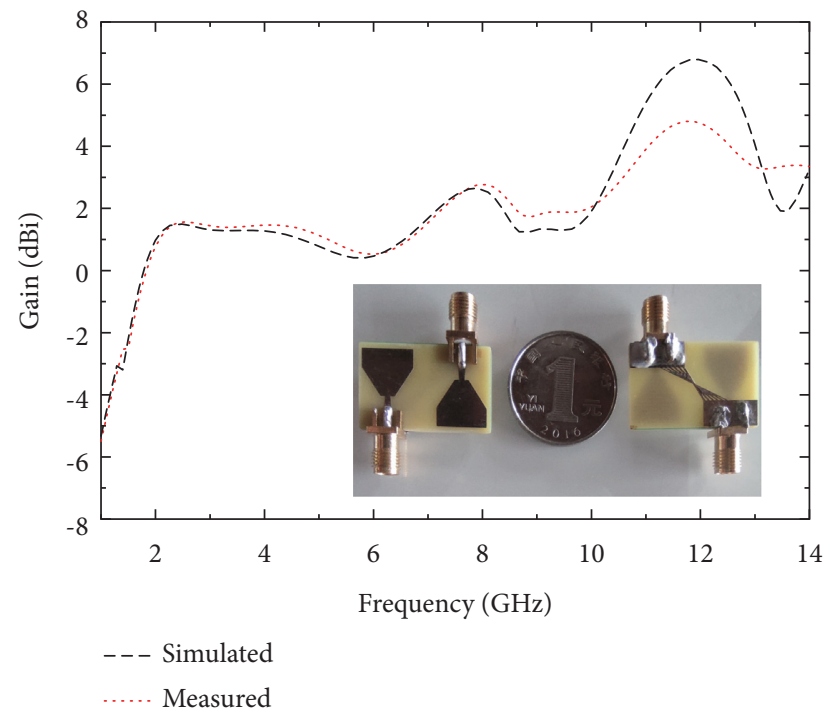

FIGURE 18: Gain graph of two-port antenna simulation and measurement.

of the angular density function of the incident wave, respectively. $\Omega$ is the solid angle of spherical coordinates [28]. Equation (6) uses the calculated ECC to calculate the diversity gain (DG). Generally, the ECC of the MIMO antenna is required to be less than 0.5 . The smaller the ECC, the larger the diversity gain (close to $10 \mathrm{~dB}$ ). It can be seen from Figure 19 that in the entire working frequency band, ECC is less than 0.09 , which is far less than the general requirement for MIMO antennas.

$$
\begin{aligned}
\rho_{e} & =\frac{\left|\int_{0}^{2 \pi} \int_{0}^{\pi}\left(X P R \cdot E_{\theta i} \cdot E_{\theta j}^{*} \cdot P_{\theta}+E_{\varphi i} \cdot E_{\varphi j}^{*} \cdot P_{\varphi}\right) \mathrm{d} \Omega\right|^{2}}{\int_{0}^{2 \pi} \int_{0}^{\pi}\left(X P R \cdot E_{\theta i} \cdot E_{\theta i}^{*} \cdot P_{\theta}+E_{\varphi i} \cdot E_{\varphi i}^{*} \cdot P_{\varphi}\right) \mathrm{d} \Omega \times \int_{0}^{2 \pi} \int_{0}^{\pi}\left(X P R \cdot E_{\theta j} \cdot E_{\theta j}^{*} \cdot P_{\theta}+E_{\varphi j} \cdot E_{\varphi j}^{*} \cdot P_{\varphi}\right) \mathrm{d} \Omega}, \\
\mathrm{DG} & =10 \sqrt{1-\left|\rho_{e}\right|^{2}} .
\end{aligned}
$$

Mean effective gain (MEG) is an important parameter to measure the diversity performance of MIMO antennas. It can be used to evaluate the ability of antenna elements to receive electromagnetic signals in a multipath fading environment [29]. The measurement result of MEG is shown in Figure 20. Measured MEG 1 and MEG 2 are close to $-3 \mathrm{~dB}$ in 


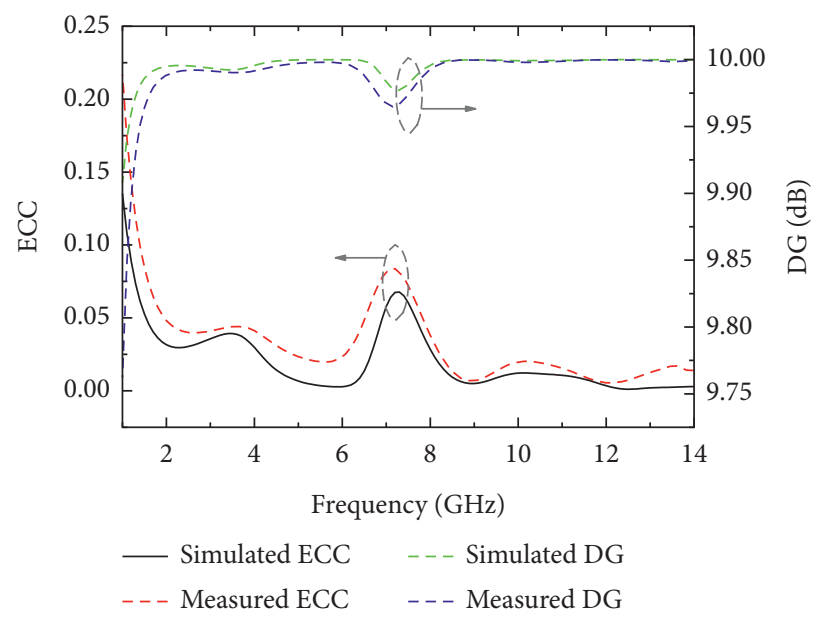

FIGURE 19: Simulation and measurement of ECC and DG results.

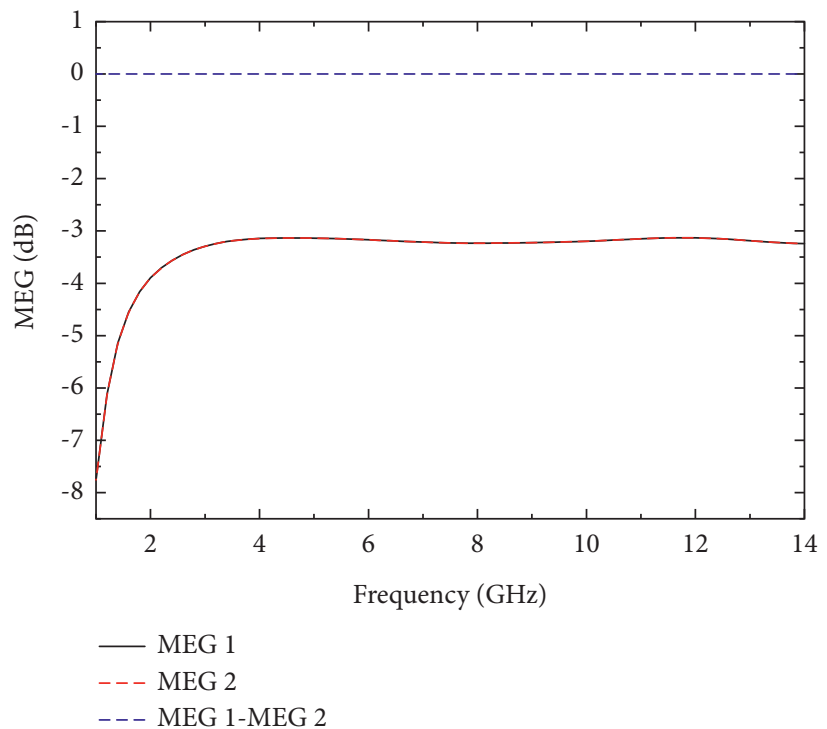

FIGURE 20: Graph of measured MEG results.

the working frequency band, and the difference between the two is maintained at $\pm 3 \mathrm{~dB}$, which meets the design requirements of MIMO antennas.

The channel capacity loss (CCL) can be used to evaluate the maximum limit value of the signal transmission rate. To increase the transmission rate, under normal circumstances, CCL should be less than $0.4 \mathrm{bit} / \mathrm{s} / \mathrm{Hz}$ [30]. Figure 21 shows the simulated and measured CCL. It can be seen from the figure that the CCL in the working frequency band is lower than $0.4 \mathrm{bit} / \mathrm{s} / \mathrm{Hz}$, which meets the design requirements of the MIMO antenna and can be used in the MIMO communication system.

Table 1 lists the performance comparison of the single antenna element, the two-port UWB MIMO antenna, and the four-port UWB MIMO antenna designed in this paper with the two-port and four-port MIMO antennas in the reference. Through the comprehensive analysis of the performance of each antenna given in the table, it can be known that the MIMO antenna designed in this article achieves a

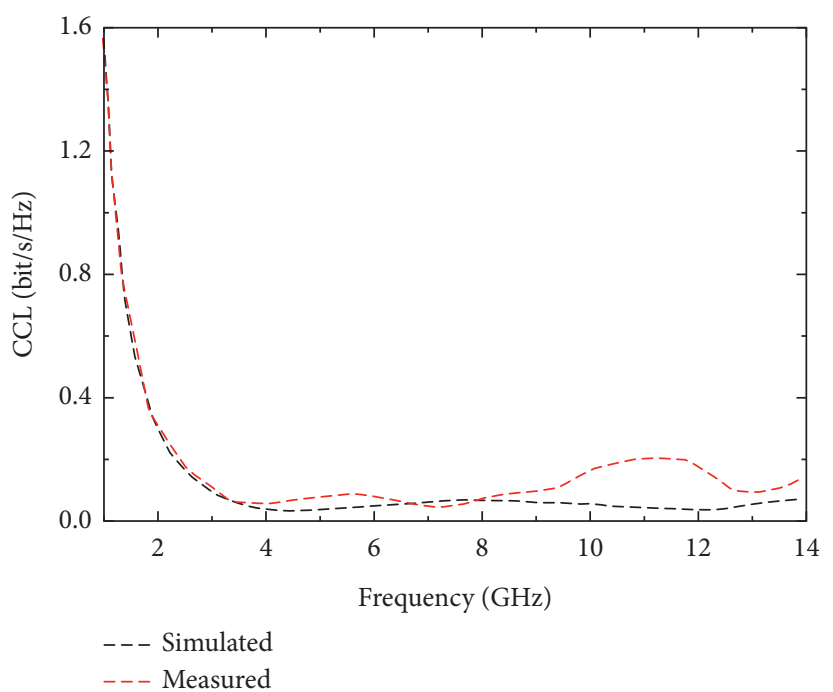

FIGURE 21: Graph of simulated and measured CCL results. 
TABLE 1: Performance comparison of proposed antenna with other reported antennas.

\begin{tabular}{|c|c|c|c|c|c|c|c|}
\hline Reference & No of elements & Dimension $\left(\mathrm{mm}^{2}\right)$ & Operating band $(\mathrm{GHz})$ & Isolation $(\mathrm{dB})$ & Method & Gain $(\mathrm{dBi})$ & ECC \\
\hline$[3]$ & 2 & $50 \times 40$ & $2.43-12$ & $>15$ & DGS & $0.4-6$ & $<0.016$ \\
\hline [4] & 2 & $24 \times 30$ & $3-12.6$ & $>16.3$ & Stub & $2-4.8$ & $<0.05$ \\
\hline \multirow{2}{*}[10]{} & 2 & $35 \times 35$ & $3-12$ & $>20$ & \multirow{2}{*}{ Diversity } & \multirow{2}{*}{ - } & \multirow{2}{*}{$<0.3$} \\
\hline & 4 & $50 \times 50$ & $3.1-10.6$ & $>15$ & & & \\
\hline [15] & 2 & $23 \times 26$ & $3.1-10.6$ & $>20$ & DGS & $2-4.5$ & $<0.01$ \\
\hline [20] & 2 & $33 \times 48$ & $2-13.7$ & $>20$ & Stub & $1.1-4.3$ & $<0.15$ \\
\hline [23] & 4 & $30 \times 30$ & $3-11$ & $>20$ & EBG & $2.5-6.8$ & $<0.006$ \\
\hline [28] & 2 & $50 \times 35$ & $3-11$ & $>25$ & DGS and stub & $4-6.2$ & $<0.004$ \\
\hline$[31]$ & 4 & $38 \times 38$ & $3-20$ & $>17$ & Diversity & $1.3-6.2$ & $<0.08$ \\
\hline [32] & 2 & $20 \times 34$ & $3.1-10.6$ & $>20$ & DGS and stub & $2-4$ & $<0.2$ \\
\hline \multirow{3}{*}{ This work } & 1 & $18 \times 12$ & $3.7-14$ & \multirow{3}{*}{$\begin{array}{l}>20.2 \\
>15.5\end{array}$} & \multirow{3}{*}{ Stubs } & \multirow{3}{*}{$0.4-4.8$} & \multirow{3}{*}{$<0.09$} \\
\hline & 2 & $18 \times 28$ & $1.9-14$ & & & & \\
\hline & 4 & $34 \times 34$ & $1.7-14$ & & & & \\
\hline
\end{tabular}

wider working frequency band and higher isolation while ensuring the miniaturization of the structure. The better gain and the ECC that meets the application requirements make the MIMO antenna designed in this article more suitable for miniaturized UWB communication equipment.

\section{Conclusions}

We designed a miniaturized high-isolation UWB MIMO antenna in this article. The isolation of the MIMO antenna is promoted by loading three crossed X-shaped stubs between the ground planes of the two antenna elements. Further, we expanded the two-port MIMO antenna to a four-port MIMO antenna. The same connection structure as the ground plane of the two-port antenna is adopted. The two $\mathrm{X}$-shaped stubs loaded between the antenna elements placed in the opposite direction are cross-connected to ensure that the antenna structure shares a ground plane. The simulation results show that the four-port antenna can achieve high isolation (greater than $15.5 \mathrm{~dB}$ ) with a wide working frequency band $(1.7-14 \mathrm{GHz})$. The measurement results show that the isolation of the two-port antenna in the $1.9-14 \mathrm{GHz}$ working frequency band is greater than $20.2 \mathrm{~dB}$, and the ECC is less than 0.09, which is far less than the generally required value. Good MEG and CCL ensure good MIMO antenna performance. Therefore, the UWB MIMO antenna has good UWB performance and excellent isolation and can be used in UWB wireless communication systems.

\section{Data Availability}

All data generated or analyzed during this study are included within this article.

\section{Conflicts of Interest}

The authors declare that there are no conflicts of interest regarding the publication of this article.

\section{Acknowledgments}

This study was supported by the National Natural Science Foundation of China (61971210).

\section{References}

[1] W. M. Saadh, K. Ashwath, P. Ramaswamy, T. Ali, and J. Anguera, "A uniquely shaped MIMO antenna on FR4 material to enhance isolation and bandwidth for wireless applications," AEU-International Journal of Electronics and Communications, vol. 123, Article ID 153316, 2020.

[2] J. Banerjee, A. Karmakar, R. Ghatak, and D. R. Poddar, "Compact CPW-fed UWB MIMO antenna with a novel modified Minkowski fractal defected ground structure (DGS) for high isolation and triple band-notch characteristic," Journal of Electromagnetic Waves and Applications, vol. 31, no. 15, pp. 1550-1565, 2017.

[3] V. Satam and S. Nema, "Two element compact UWB diversity antenna with combination of DGS and parasitic elements," Wireless Personal Communications, vol. 98, no. 3, pp. 29012911, 2018.

[4] R. Gurjar, D. K. Upadhyay, B. K. Kanaujia, and A. Kumar, “A compact modified Sierpinski carpet fractal UWB MIMO antenna with square-shaped funnel-like ground stub," AEU-International Journal of Electronics and Communications, vol. 117, Article ID 153126, 2020.

[5] A. Iqbal, A. Altaf, M. Abdullah, M. Alibakhshikenari, E. Limiti, and S. Kim, "Modified U-shaped resonator as decoupling structure in MIMO antenna," Electronics, vol. 9, no. 8, p. 1321, 2020.

[6] M. Irshad Khan, M. I. Khattak, S. U. Rahman, A. B. Qazi, A. A. Telba, and A. Sebak, "Design and investigation of modern UWB-MIMO antenna with optimized isolation," Micromachines, vol. 11, no. 4, p. 432, 2020.

[7] S.-W. Su, C.-T. Lee, and F.-S. Chang, "Printed MIMO-antenna system using neutralization-line technique for wireless USB-dongle applications," IEEE Transactions on Antennas and Propagation, vol. 60, no. 2, pp. 456-463, 2012.

[8] S. Wang and Z. W. Du, "Decoupled dual-antenna system using crossed neutralization lines for LTE/WWAN smartphone applications," IEEE Antennas and Wireless Propagation Letters, vol. 14, pp. 523-526, 2015.

[9] R. N. Tiwari, P. Singh, and B. K. Kanaujia, "A compact UWB MIMO antenna with neutralization line for WLAN/ISM/ mobile applications," International Journal of RF and Microwave Computer-Aided Engineering, vol. 29, no. 11, Article ID e21907, 2019.

[10] J. Zhu, S. Li, B. Feng, L. Deng, and S. Yin, "Compact dualpolarized UWB quasi-self-complementary MIMO/diversity 
antenna with band-rejection capability," IEEE Antennas and Wireless Propagation Letters, vol. 15, pp. 905-908, 2016.

[11] Y. Sharma, D. Sarkar, K. Saurav, and K. V. Srivastava, "Threeelement MIMO antenna system with pattern and polarization diversity for WLAN applications," IEEE Antennas and Wireless Propagation Letters, vol. 16, pp. 1163-1166, 2017.

[12] D. A. Sehrai, M. Asif, N. Shoaib et al., "Compact quad-element high-isolation wideband MIMO antenna for mm-wave applications," Electronics, vol. 10, no. 11, p. 1300, 2021.

[13] X. Yang, Y. Liu, Y.-X. Xu, and S.-X. Gong, "Isolation enhancement in patch antenna array with fractal UC-EBG structure and cross slot," IEEE Antennas and Wireless Propagation Letters, vol. 16, pp. 2175-2178, 2017.

[14] E. Thakur, N. Jaglan, and S. D. Gupta, "Design of compact triple band-notched UWB MIMO antenna with TVC-EBG structure," Journal of Electromagnetic Waves and Applications, vol. 34, no. 11, pp. 1601-1615, 2020.

[15] B. Yang, M. Chen, and L. Li, "Design of a four-element WLAN/LTE/UWB MIMO antenna using half-slot structure," AEU-International Journal of Electronics and Communications, vol. 93, pp. 354-359, 2018.

[16] B. Azarm, J. Nourinia, C. Ghobadi, M. Majidzadeh, and N. Hatami, "A compact WiMAX band-notched UWB MIMO antenna with high isolation," Radioengineering, vol. 27, no. 4, pp. 983-989, 2018.

[17] T. Addepalli and V. R. Anitha, "A very compact and closely spaced circular shaped UWB MIMO antenna with improved isolation," AEU - International Journal of Electronics and Communications, vol. 114, Article ID 153016, 2020.

[18] T. Addepalli, A. Desai, I. Elfergani et al., "8-port semi-circular arc MIMO antenna with an inverted L-strip loaded connected ground for UWB applications," Electronics, vol. 10, no. 12, p. 1476, 2021.

[19] H. T. Chattha, F. Latif, F. A. Tahir, M. U. Khan, and X. Yang, "Small-sized UWB MIMO antenna with band rejection capability," IEEE Access, vol. 7, pp. 121816-121824, 2019.

[20] A. Altaf, A. Iqbal, A. Smida et al., "Isolation improvement in UWB-MIMO antenna system using slotted stub," Electronics, vol. 9, no. 10, p. 1582, 2020.

[21] S. Zhang and G. F. Pedersen, "Mutual coupling reduction for UWB MIMO antennas with a wideband neutralization line," IEEE Antennas and Wireless Propagation Letters, vol. 15, pp. 166-169, 2016.

[22] R. Gómez-Villanueva and H. Jardón-Aguilar, "Compact UWB uniplanar four-port MIMO antenna array with rejecting band," IEEE Antennas and Wireless Propagation Letters, vol. 18, no. 12, pp. 2543-2547, 2019.

[23] P. Palanisamy and M. Subramani, "Novel double-side EBG based mutual coupling reduction for compact quad port UWB MIMO antenna," AEU-International Journal of Electronics and Communications, vol. 109, pp. 146-156, 2019.

[24] W. A. E. Ali and A. A. Ibrahim, "A compact double-sided MIMO antenna with an improved isolation for UWB applications," AEU-International Journal of Electronics and Communications, vol. 82, pp. 7-13, 2017.

[25] A. Talha and A. T. Farooq, "A miniaturized triple bandnotched UWB antenna," Microwave and Optical Technology Letters, vol. 59, no. 10, pp. 2581-2586, 2017.

[26] S. Kundu, "Experimental study of a printed ultra-wideband modified circular monopole antenna," Microwave and Optical Technology Letters, vol. 61, no. 5, pp. 1388-1393, 2019.

[27] M. S. Sharawi, "Current misuses and future prospects for printed multiple-input, multiple-output antenna systems [wireless corner]," IEEE Antennas and Propagation Magazine, vol. 59, no. 2, pp. 162-170, 2017.

[28] L. Wang, Z. Du, H. Yang et al., "Compact UWB MIMO antenna with high isolation using fence-type decoupling structure," IEEE Antennas and Wireless Propagation Letters, vol. 18, no. 8, pp. 1641-1645, 2019.

[29] R. Chandel, A. K. Gautam, and K. Rambabu, "Tapered fed compact UWB MIMO-diversity antenna with dual bandnotched characteristics," IEEE Transactions on Antennas and Propagation, vol. 66, no. 4, pp. 1677-1684, 2018.

[30] A. Kumar, A. Q. Ansari, B. K. Kanaujia, and J. Kishor, "High isolation compact four-port MIMO antenna loaded with CSRR for multiband applications," Frequenz, vol. 72, no. 9-10, pp. 415-427, 2018.

[31] W. Yin, S. Chen, J. Chang, C. Li, and S. K. Khamas, "CPW fed compact UWB 4-element MIMO antenna with high isolation," Sensors, vol. 21, no. 8, p. 2688, 2021.

[32] J. Prasanth Kumar and G. Karunakar, "Compact UWBMIMO triple notched antenna for isolation reduction," Wireless Personal Communications, vol. 115, no. 3, pp. 2113-2125, 2020. 